University of Nebraska - Lincoln

DigitalCommons@University of Nebraska - Lincoln

June 2006

\title{
The Inadequacy of Forrester System Dynamics Computer Programs for Institutional Principles of Hierarchy, Feedback, and Openness
}

F. Gregory Hayden

University of Nebraska - Lincoln, ghayden1@unl.edu

Follow this and additional works at: https://digitalcommons.unl.edu/cbafacpub

Part of the Business Commons

Hayden, F. Gregory, "The Inadequacy of Forrester System Dynamics Computer Programs for Institutional Principles of Hierarchy, Feedback, and Openness" (2006). College of Business Faculty Publications. 14. https://digitalcommons.unl.edu/cbafacpub/14

This Article is brought to you for free and open access by the Business, College of at DigitalCommons@University of Nebraska - Lincoln. It has been accepted for inclusion in College of Business Faculty Publications by an authorized administrator of DigitalCommons@University of Nebraska - Lincoln. 


\section{The Inadequacy of Forrester System Dynamics Computer Programs for Institutional Principles of Hierarchy, Feedback, and Openness}

\section{F. Gregory Hayden}

The purpose here is to discuss the institutional systems principles of hierarchy, feedback, and openness, and to explain the inadequacy of Forrester-type system dynamics programs to apply those principles.

\section{Hierarchy}

It is the function of some system components to control what happenings are to happen, and to determine where, when, how, and to what extent they are to happen. Hierarchies exist to ensure that the happenings are happening as they should happen. The various system components that form the more powerful level in a structural hierarchy exert specific directives on the activities and deliveries of other components through a variety of forms that establish different kinds of control paths among institutional organizations.

Hierarchies contain many different kinds of criteria, rules, controls, regulations, and so forth. Technology is an example of system controls, as it provides criteria that must be met in a social system. Rules, regulations, and requirements are established in particular social settings to establish controls and sanctions necessary to meet normative criteria. Karl Polanyi used the concepts of permission, obligation, and prohibition to categorize criteria and control sets. John Commons clarified that system action, which includes exchange transactions, used the auxiliary verbs can, cannot, must, must not, may or may not do in order to categorize collective sanctions.

The author is Professor of Economics, University of Nebraska-Lincoln, USA. This paper was presented at the annual meeting of the Association for Evolutionary Economics in Boston January 6-8, 2006. 
Figure 1 was presented by Robert Boyer as a summary of the "new institutional economics" concept of rules for the hierarchical relationships among the entries contained in the figure, about which he stated that the definitions indicate "a clear hierarchy" (2001, 85-89). Boyer's statement that the relationships among the entities in figure 1 are "Top-down: From the constitution to individuals: a clear hierarchy" (88) is an attempt to make hierarchy into a spatial order, rather than an institutional process, and to confirm a hierarchical concept by the placement of geometric figures on a page. Hierarchy is not a matter of the spatial concept of up and down, and figure 1 is not a clear top-down hierarchy. The order and placement of the figures could be changed and not change the meaning.

Figure 1 is a very misleading rendition of complex systems. The process of constitutionality and rulemaking is not a linear order connected with pluses and minuses. Constitutional order is an expression of a complex network that is established, renewed, and

Figure 1. Relationships among Constitutional Order, Institutions, Organizations, and Conventions

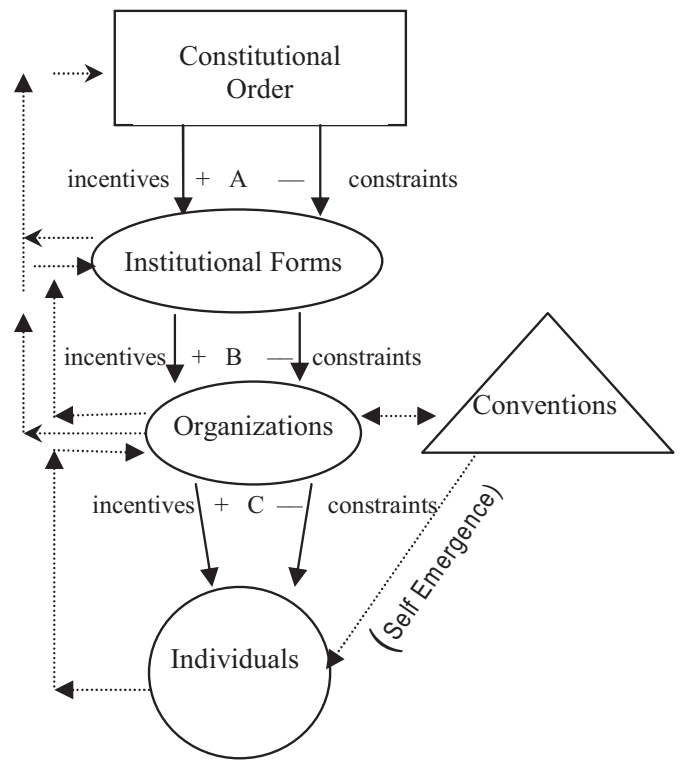

Top-down: From the constitution to individuals; a clear hierarchy: $\mathrm{A} \rightarrow \mathrm{B} \rightarrow \mathrm{C}$.

Bottom-up: Emerging disequilibria and conflicts call for a revision of upper level rules of the game.

Degree of persistence: Constitutional Order $>$ Institutional Forms $>$ Organizations $>$ Individuals 
processed through institutions. Furthermore, institutions are guided by cultural values and normative criteria (see Hayden 1998), which are absent from figure 1. To have regulative power, constitutional activity has to be established in the various institutional organizations that are part of complex systems. Constitutional order is not an entity separate from institutions. In reality, constitutionality is expressed as a set of processes, flows, and deliveries within and among institutional organizations.

Furthermore, figure 1 is misleading because it has rulemaking in the top part of the figure but not the lower. First, the formulation of rules is spread throughout the socioecological matrix, and rules are constructed to be consistent with a whole array of normative criteria. For example, if a rule is established in bridge building that there is to be a three-inch weld every twelve inches, that rule has been established in response to criteria for concerns such as safety, monetary cost, wind conditions, and so forth. Second, "informal habits and ideology are expected to play a role in constitutional change as well as feedback from the performance of existing everyday-level institutions" (Schmid 2004, 3). Third, institutions that make rules must also use rules for making rules that come from other institutions, and "the rules for changing rules affect how everyday rules might be changed."

The institutions that make up constitutional processes are working institutions and not an entity positioned on high as depicted in figure 1. Constitutional processes are part of a socioecological network; constitutional rulings can come from many different kinds of institutions and organizations, and their rulings change with new interpretations directed by other institutions, for example, political institutions. Constitutional decisions in institutions operate according to the complex system surrounding the institutions.

Deliveries among institutions and organizations are not a matter of simple pluses and minuses, as indicated in figure 1 . The deliveries from court rulings, for example, are delivered by other institutions, such as police departments delivering arrests, schools delivering instruction, and pharmacies delivering methods of birth control-hardly plus and minus categories. Are rules that increase monetary costs for corporations considered minuses because corporations try to avoid them? It is through such costs that most beneficial flows are provided-incomes, environmental protection, product safety, cancer prevention, and so forth. So would such rules get a plus or a minus? One set of collective rules establishes accounting principles that require accountants to designate payments to labor as a cost, while economic development laws and rules require accountants to designate the same payments to labor as a positive benefit.

\section{Control Paths: Feedback and Feedforward}

A system as a processing unit has no forward or backward; lots of befores and afterwards regularly repeat themselves, so that some afterwards come before the next cycle of befores. Thus, it makes as much sense to talk about feedforwards as feedbacks in a com- 
plex system. Feedback is a form of inter- and intra-systemic control in which the performance of the system utilizes information, requirements, materials, violence, criteria, rules, evaluation research, inventories, semiotic signs, money flows, and other deliveries to guide a system. Hierarchy is one reason for feedback.

Negative feedback processes are error activated and goal seeking in that the goal state is compared with the actual deliveries and deviations in order to direct the system toward the goal state. "Negative feedback, thus, leads to the convergence of system behavior toward some goal" (Hayden 2006, 58). Positive feedback processes, in which positive feedback overwhelms negative feedback, tend to be destructive to the system because a change in the original level of the system provides an input for further change in the same direction.

The feedback concept comes from cybernetics, where feedback means devices in a mechanical system to counter entropy. The conservation process for energy also conserves information, and, as a consequence, information became the main concern of cybernetics. The founder of cybernetics, Norbert Wiener, recommended caution in trying to apply the feedback concept in cybernetics to the social sciences (Gjessling 1968, 11). Cybernetics is mechanistic, based on physics, and very concerned with energetics-hardly the base for studying feedback control in social systems. Social systems are much too open, irregular, and dynamic for a mechanistic theory to apply. Contrary to Wiener's warning, feedback has usually been implemented in social science models as a simple one-dimensional information construct, as expressed by the bottom-up arrows in figure 1 .

In contrast to figure 1 , the network in figure 2 demonstrates the complexity and extensiveness of constitutional order, hierarchy, and control paths. Figure 2 is a digraph expression of part of a social fabric matrix for the management of the surface water of the Platte River in Nebraska (USA) (Yang 1996, 237-256). The parentheses on the edges indicate delivery cells in the social fabric matrix (238). The system requires water users to obtain water-use rights through an application process. Figure 2 is the application process among organizations to obtain the water-use rights. Application processes are among the most important activities of rulemaking.

Figure 2 clarifies that (1) the whole system must function together in order for it to be effective; (2) the ecological systems and institutional systems are integrated and sustain each other; (3) the process is not confined to top-down relationships; (4) institutional connectivity is crucial to constitutionality, control, and regulation; and (5) feedback control paths in a social system are sets of institutional processes at work. Examples of application activities include:

- Edge (8,18): The Water Management Board sends a notice of rejection or acceptance, along with policy criteria and 75 percent of the project cost if approved, in response to an application for a water-use project from Instream Water Users I (1. Game and Parks Commission). 
Figure 2. Relationships among Regulatory Organizations and Water Users' Organizations in the Application Process for Water Use

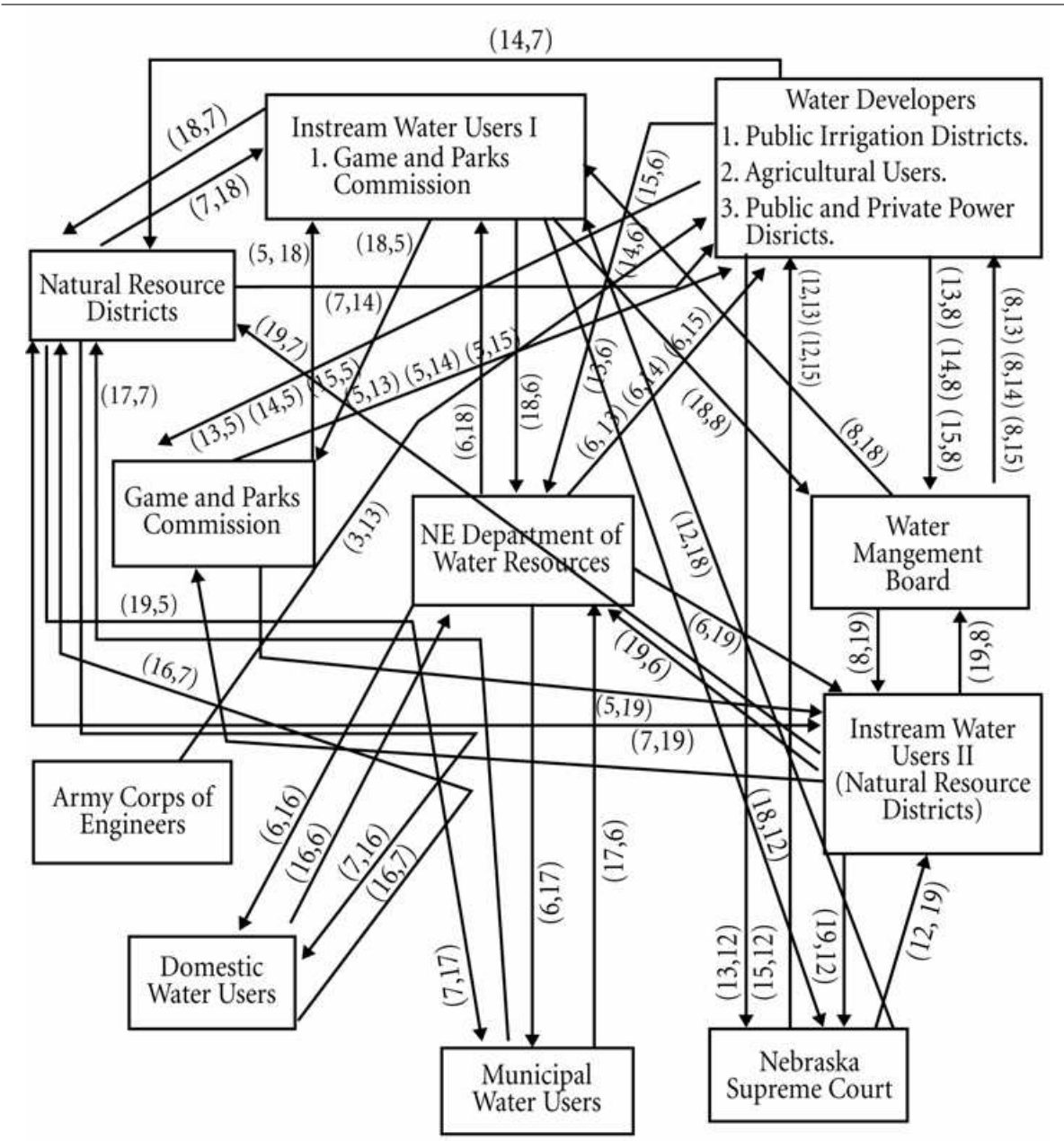

Source: Yang 1996.

- Edge (7,17): Reflects the requirements of Natural Resource Districts for Municipal Water Users as part of the Natural Resource Districts' control over groundwater use.

- Edge $(6,19)$ : In response to instream appropriation applications from Instream Water Users II, the Nebraska Department of Water Resources delivers, if approved, the notice of acceptance of projects for recreation or fish and wildlife purposes. 
- Edges $(18,12),(19,12)$ and $(13,12)$ : To keep the system processing, conflicts must be delivered to the appropriate agencies for resolution. These three edges indicate deliveries as a result of conflicts among the Game and Parks Commission, Instream Water Users II (Natural Resource Districts), and Water Developers. The conflicts are delivered to the Nebraska Supreme Court for adjudication.

These examples clarify that for constitutional order and control paths to function, a network of deliveries must be processing.

\section{Openness}

Openness is a characteristic of all systems and therefore needs to be recognized in institutional modeling. Openness means that there is a diverse environment surrounding any system and that there are continuous flows of energy, information, materials, and ideas from the environment to the system and from the system to the environment. The system is defined in detail, but the external environment is not, because the only interest in the environment is how it impacts on the system. Because real-world systems are constantly open to their environments, equilibrium is not possible.

Openness was discovered and articulated first in the physical and biological sciences; thus, scholars and policy makers often do not recognize that social systems are much more open and dynamic than traditional systems literature indicates. First, "part of an organization is the behavior of other organizations" (Schmid 2004, 262), including other organizations in the environment. Second, extreme diversity exists in the environment surrounding any social or economic system. Third, myriad optional and contingent components can begin functioning in the environment, opening the system to new influences. Fourth, environments evolve through differentiation and elaboration. Fifth, the social world surrounding a system changes because it establishes institutions for enhancing change: courts, for example. Sixth, environments change because technology continues to differentiate.

The rendition of system organizations in figure 1 allows for change to be implemented only from changes within the system. There is no environment indicated and, thus, no openness. The same incorrect assumption is made for Forrester-type system dynamics computer programs.

\section{Forrester System Dynamics Computer Programs}

The computer programs for Forrester system dynamics computer programs are inadequate for expressing the characteristics of hierarchy, feedback, and openness as understood in institutional economics (OIE) because of the unique conceptualizations in the Forrester tradition. 
Jay Forrester developed his analysis for electrical engineering systems and applied it, along with the positive and negative charges of electricity, to social science problems, as in figure 3. Thus, the main problem with Forrester-type computer programs is the focus on the pluses and minuses of closed electrical programs, while the basic building blocks of the social sciences are institutions, normative criteria, rules, and so forth (see Parto 2005).

\section{Mimicry Is Not Modeling}

Forrester systems literature emphasizes that models are to mimic databases, meaning that coefficients are to be adjusted with the capabilities of the computer program until the model will reproduce historical database results for particular entities of interest. "Employing systems dynamics involves specifying the mathematical relationships among the various objects deemed to be parts of the system under study and then making adjustments to the parameters until historical inputs generate historical outputs" (Harvey and Klopfenstein 2001, 441-442). If the goal is to juggle data and manipulate coefficients until a particular historical data path is reproduced, what the nodes in the model are called or how they work in the real world is not a concern. It is coefficient adjustments that generate validity. The coefficients are not adjusted because of statistical analysis or institutional theory but, rather, to reproduce a database.

Figure 3. Influence Diagram of Patterns of Interactions in Hog Production Environmental Regulation in Quebec

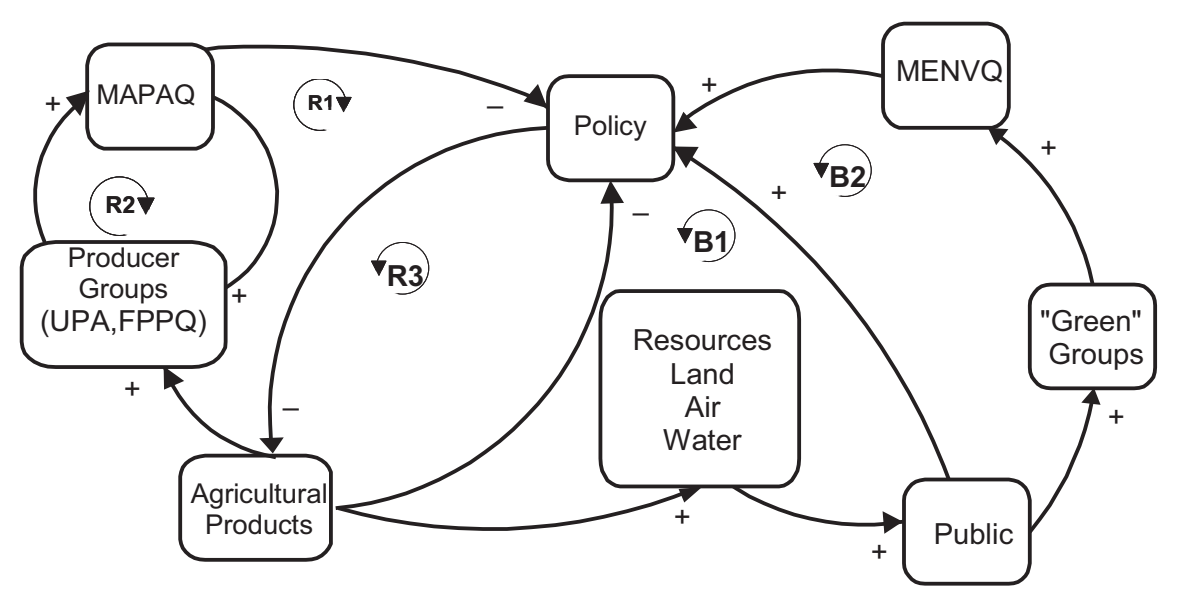

Source: Thomassin and Cloutier 2004. 


\section{Plus and Minus Adjustments as Substitutes for Theory and Observed Relationships}

Within most Forrester dynamics programs, there is the capability to attach any two entities in a program mapping and "tweak" the real or imagined connections with plus or minus charges to indicate influence, or support, or opposition, or causes, or whatever. Plus and minus charges are utilized to create a mapping that results from feedback loops that influence the activity nodes. "Following established syntax, the '+' and '?' signs on the diagram denote 'supporting' and 'opposing' influences, or causes, respectively. These influences form closed loops that represent either reinforcing or balancing feedback structures within the system. The interaction of these feedback loops, and at times the domination of the process by any of the loops, causes pressures, instability, and dynamic behavior of the system over time" (Thomassin and Cloutier 2004, 499). With regard to figure 3, Paul Thomassin and Martin Cloutier stated, "The influence diagram is meant to illustrate the policy, organizational, and operational pressures associated with the conflict of interest in hog production with the public" (498). So what are the details in figure 3? What is the positive charge that "land" gives the "Public?" What does the "Public" mean? Is it a court, agency, or legislative body, or is it what John Dewey defined as the public? Where are the normative criteria that guide the socioecological process? It may not matter, because the authors state that the purpose is to estimate "potential outcome" and "imagined situations" (498).

\section{Plus and Minus Approach to Modeling}

The plus and minus approach to modeling social problems should not be substituted for social systems theory and observed relationships for numerous reasons.

First, changing pluses and minuses to obtain databases that preceded the model does not provide analysts with modeling to determine whether the databases correctly reflect the system.

Second, the Forrester definition of dynamics is inconsistent with that found in general systems theory. For Forrester, dynamics is a result of predetermined feedback loops that must be defined within the system. As explained above, dynamics is the result of the relationships between the system and the undefined activity in the surrounding environment. Forrester programs exclude openness. Instead, the Forrester approach is to force the construction of feedback loops within system boundaries in order to create behavior. This is contrary to the institutional approach, in which interest is in the observation and modeling of real-world behavior that includes system openness to surrounding environments.

Third, Forrester dynamics experts claim that level and rate variables are sufficient elements for defining a system. However, a rate is just a mathematical expression, calculated from levels. In reality, levels are flow deliveries among institutions and between institutions and ecological systems. The delivery levels are guided by other institutions 
that regulate, monitor, and enforce according to normative criteria-not pluses, minuses, and rates. The latter are inadequate to explain or understand a social system. Normative criteria, rules, regulations, and requirements guide the level-to-level relationships in the real-world sociological systems, not mathematical artifacts.

\section{Conclusion}

In institutional economics, the concepts of hierarchy, feedback, and openness are consistent with (1) general systems analysis, (2) the treatment of hierarchy and feedback as part of complex system networks, and (3) system dynamics that result from a system being open to its environment. Thus, it is inappropriate to adopt the definitions of these concepts as they are defined in "new institutional economics" and inadequate to utilize Forester-type computer programs to apply them for analysis of real-world systems. Figure 2 demonstrates that the real-world hierarchical systems that provide for constitutionality, rulemaking, and control are the consequence of integrated organizations that are sustained through a network of system criteria and deliveries. A constant set of normative criteria in a stable system can lead to requirements for diverse kinds, different distributions, varying quantities, and either increases or decreases of delivery levels among the same organizations given different situations. Thus, the simple idea of modeling relationships among organizations and between systems and the environment like plus and minus electrical charges as required by Forester-type computer programs is inconsistent with institutional economics.

\section{References}

Boyer, Robert. "The Regulation Approach as a Theory of Capitalism: A New Derivation." In Institutional Economics in France and Germany, edited by Agnès Labrousse and Jean-Daniel Weisz. Berlin: Springer, 2001.

Gjessling, Gutorm. Complementarity, Value, and Socio-Cultural Field. Oslo: Universitetsforlaget, 1968.

Harvey, John T., and Kristin Klopfenstein. "International Capital and Mexican Development: A System Dynamics Model." Journal of Economic Issues 35 (June 2001).

Hayden, F. Gregory. "Normative Analysis of Instituted Processes." In Institutionalist Theory and Applications: Essays in Honour of Paul Dale Bush, edited by Sasan Fayazmanesh and Marc R. Tool, 89-107. Boston: Cheltenham, U.K.: Edward Elgar, 1998.

—. Policymaking for a Good Society: The Social Fabric Matrix Approach to Policy Analysis and Program Evaluation. New York: Springer, 2006.

Parto, Saeed. "Economic Activity and Institutions: Taking Stock." Journal of Economic Issues 39 (March 2005).

Schmid, A. Allan. Conflict and Cooperation: Institutional and Behavioral Economics. Malden, Mass.: Blackwell Publishing, 2004.

Thomassin, Paul, and Martin Cloutier. "The Evolution of Environmental Legislation: A Strategic Transaction Approach.” Journal of Economic Issues 38 (June 2004).

Yang, Youngseok. "Crafting Hierarchical Institutions for Surface Water Resource Management of the Platte River: A Case Study for the Assessment of Institutional Performance and Transformation.” Ph.D. dissertation, University of Nebraska, Lincoln, Neb., 1996. 